\title{
Incidence and risk factors of surgical site infection in a tertiary health institution in Kano, Northwestern Nigeria
}

\author{
Nwankwo EO' ${ }^{1}$, Ibeh IN², Enabulele $\mathrm{OI}^{2}$ \\ 1 Department of Microbiology and Parasitology, Faculty of Medicine, Bayero University Kano, Nigeria \\ ${ }^{2}$ Department of Microbiology, Faculty of Life Sciences, University of Benin, Benin city, Nigeria
}

\begin{abstract}
Surgical site infection (SSI) is the most common complication following surgical procedures. The aim of this study was to determine the incidence and associated risk factors of surgical site infection in a tertiary health institution in Kano, Nigeria.
\end{abstract}

The study was carried out between January 2008 and December 2010. Data was collected in a predesigned questionnaire forms which focused on demographic details, socioeconomic background and lifestyle while the diagnosis, surgical procedure, duration of surgery, prophylactic antibiotics, postoperative antibiotics and co-morbidity were obtained from the patients hospital records. All the patients who underwent surgery in the male and female surgical wards, gynaecology and maternity wards including paediatric wards were enrolled in the study after informed consent of patients or parents in the case of children. All patients were followed up for 30 days for development of surgical site infection. Infected cases were identified using CDC, USA definition for surgical site infections. Out of 2880 patients, $585(20.3 \%)$ were confirmed to be clinically infected (SSI). There were 1,016 (35.3\%) males with a mean age of $38.3 \pm 16.3$ and 1864 females $(64.9 \%)$, mean age $30.6 \pm 12.3 y r s$. There were $65 \%$ Superficial Incisional SSI, 30\% deep Incisional SSI and 5\% Organ Space SSI. Incidence related to clean, clean contaminated, contaminated and dirty were $5.8 \%, 30.5 \%, 40.6 \%$, and $64.8 \%$ wounds respectively. Age, anaemia, obesity, number of persons in operating room and duration of surgery were all significantly associated with SSI. Effective infection control measures and good regular surveillance will improve the SSI rate to an acceptable level.

Key words

Surgical wound infection+epidemiology; Risk factors; Nigeria

\section{Corresponding Author}

Nwankwo E.O

P.O. Box 2367, Kano, Nigeria

Email: emmaonwubiko@yahoo.com

Tel: +2348023309146 


\section{Introduction}

Surgical site infections are among the most common hospital acquired infections. They make up to $14-16 \%$ of inpatient infections. ${ }^{1}$ It is an unwanted situation, a burden on the patient and social health system. ${ }^{2}$ In spite of the technological advances that have been made in surgery and wound management, wound infection has been regarded as the most common nosocomial infection especially in patients undergoing surgery. ${ }^{3}$ It is an important cause of illness resulting in a prolongation of hospital stay, increased trauma care, treatment costs and general wound management practices become more resource demanding. ${ }^{4}$

While the global estimates of SSI have varied from $0.5-15 \%,{ }^{5}$ studies in India have consistently shown higher rates ranging from $23-28 \%,{ }^{6}$ while a report from Tanzania showed an incidence rate of $19.4 \%{ }^{7}$

The importance of wound infections in both economic and human terms, should not be underestimated. Practitioners need to know how to recognize and manage the signs and consequences of clinically infected wounds. ${ }^{8}$ Knowledge of the incidence rate and evaluation of associated risk factors will be of immense value to surgeons, operating room personnel and infection control practitioners in this institution.
This will enhance infection control practices. There is paucity of data on this subject in this locality; hence, this study was deemed necessary.

\section{Patients and methodology}

Study design: A prospective cross sectional study was carried out from January, 2008 to December, 2010.

Study setting: Aminu Kano Teaching Hospital (AKTH) is a tertiary care hospital in Kano, Northwestern Nigeria with about 1000 beds. It provides a high level medical care to a large population of people. The study was carried out in male and female surgical wards, maternity, gynaecology and paediatric surgical wards where both emergency and elective procedures were performed. In the study period no procedure with implant was performed.

Sample size: A total of 2880 consecutive patients who underwent surgery during that period were enrolled after informed consent of patients or parents in the case of children.

Case definition: An SSI case was identified using CDC USA definition which states that infection would be regarded as SSI if it occurs within 30 days of procedure and has at least one of the following; purulent drainage

Table I. Age, sex and infection rate distribution among surgical site infected patients at AKTH

\begin{tabular}{rrrrrr} 
Age & Male (\%) & Female (\%) & $\begin{array}{r}\text { No. of patients } \\
\text { Infected }\end{array}$ & $\begin{array}{r}\text { Number } \\
\text { in study }\end{array}$ & $\begin{array}{r}\text { Infection rate } \\
\mathbf{( \% )}\end{array}$ \\
\hline $0-10$ & $20(7.3)$ & $15(4.8)$ & $35(5.9)$ & 461 & 7.5 \\
$11-20$ & $26(9.5)$ & $40(12.8)$ & $66(11.2)$ & 354 & 18.6 \\
$21-30$ & $60(21.9)$ & $91(29.2)$ & $151(25.7)$ & 672 & 22.5 \\
$31-40$ & $51(18.8)$ & $49(15.7)$ & $100(17.5)$ & 499 & 20.0 \\
$41-50$ & $36(13.2)$ & $21(6.7)$ & $57(9.7)$ & 287 & 19.9 \\
$51-60$ & $36(13.2)$ & $32(10.3)$ & $68(11.6)$ & 235 & 28.9 \\
$61-70$ & $26(9.5)$ & $29(9.3)$ & $55(9.4)$ & 201 & 27.4 \\
$>70$ & $18(6.6)$ & $35(11.2)$ & $53(9.0)$ & 171 & 30.9 \\
\hline TOTAL & $\mathbf{2 7 3}$ & $\mathbf{3 1 2}$ & $\mathbf{5 8 5}$ & $\mathbf{2 8 8 0}$ & $\mathbf{2 0 . 3}$ \\
\hline$X_{\text {trend }}^{2}=4.91$ p $<0.0001$ & & & &
\end{tabular}


Table II. Infection rate by service units among surgical patients at AKTH

\begin{tabular}{rrrrr} 
Service units & $\begin{array}{r}\text { No. of } \\
\text { patients in study }\end{array}$ & $\begin{array}{r}\text { Percentage } \\
(\mathbf{\%})\end{array}$ & $\begin{array}{r}\text { Number } \\
\text { infected }\end{array}$ & $\begin{array}{r}\text { Infection rate } \\
\mathbf{( \% )}\end{array}$ \\
\hline Male surgical ward & 1016 & 35.3 & 264 & 25.9 \\
Female surgical ward & 609 & 21.1 & 93 & 15.3 \\
Post natal ward & 611 & 21.3 & 132 & 21.6 \\
Gynaecology ward & 394 & 13.6 & 66 & 16.7 \\
Paediatric ward & 250 & 8.7 & 30 & 12.0 \\
\hline Total & $\mathbf{2 8 8 0}$ & & $\mathbf{5 8 5}$ & $\mathbf{2 0 . 3}$ \\
\hline
\end{tabular}

$X^{2}=4.41$, df $4 p<0.0001$

from the wound, pain or tenderness, localized swelling, redness, malodour, fever. A questionnaire was filled for each patient to collect data on demographic details, life style while other parameters such as clinical diagnosis, pre and postoperative antibiotics, haemoglobin level before and after surgery among others were obtained from the medical records. The predesigned questionnaire which was used had been validated by other researchers with slight modifications to suite this present study. ${ }^{9}$

Statistical analysis: Percentages were calculated for categorical variables like gender. Data were analysed using EPI info Version 6 and SPSS 14. Multiple logistic regression models were used to measure the magnitude and significance of the association between SSI and risk factors. The strength of association between various factors and SSI were reported in terms of odds ratio. The role of chance was evaluated and reported in terms of $95 \%$ confidence interval and $P$ value.

\section{Results}

Out of a total of 2880 patients enrolled in the study, $1,016(35.3 \%)$ were males and 1,864 (64.7\%) were females. Mean age of the female patients was 30.6 \pm 12.3 years and male patients $38.3 \pm 16.3$ years. An infection rate of $20.3 \%$ of SSI was observed in this study. There were $65 \%$ Superficial Incisional

Table III. Multiple logistic regression analysis of Risk factors in SSI in AKTH

\begin{tabular}{lrrrrrrrr} 
Predictor & Coefficient & $\begin{array}{c}\text { Standard } \\
\text { deviation }\end{array}$ & & & $\mathbf{P}$ & $\begin{array}{c}\text { Odds } \\
\text { ratio }\end{array}$ & \multicolumn{2}{r}{$\mathbf{9 5 \%} \mathbf{~ C l}$} \\
\hline Constant & -7.387 & 1.598 & -4.62 & $<0.001$ & & & & \\
Age & -0.03282 & 0.02309 & -1.42 & 0.155 & 0.97 & 0.92 & 1.01 \\
Sex & 0.0089 & 0.3804 & -0.02 & 0.981 & 0.99 & 0.47 & 2.09 \\
Anemia & 1.2449 & 0.4045 & 3.08 & 0.002 & 3.47 & 1.57 & 7.67 \\
Obesity & 1.7022 & 0.4089 & 4.16 & $<0.001$ & 5.49 & 2.46 & 12.23 \\
Duration & 1.3273 & 0.4040 & 3.29 & 0.001 & 3.77 & 1.71 & 8.32 \\
No. on operation list & 0.4645 & 0.3883 & 1.20 & 0.232 & 1.59 & 0.74 & 3.41 \\
No. of persons in operation & 0.8971 & 0.4041 & 2.22 & 0.026 & 2.45 & 1.11 & 5.41 \\
room & & & & & & & \\
Cigarette & 0.7450 & 0.4492 & 1.66 & 0.097 & 2.11 & 0.87 & 5.08 \\
Diabetes & 1.8707 & 0.4403 & 4.25 & $<0.001$ & 6.49 & 2.74 & 15.39
\end{tabular}


SSI, 30\% deep Incisional SSI and 5\% Organ Space SSI. Incidence related to clean, clean contaminated, contaminated and dirty were 5.8\%, 30.5\%, 40.6\%, and $64.8 \%$ wounds respectively.

Table I shows the age, sex and infection rate distribution among SSI patients in AKTH. Postoperative wound infection developed in $585(20.3 \%)$ patients. Of these, $273(46.7 \%)$ were males while $312(53.3 \%)$ were females. While $0-10 \mathrm{yrs}$ had the least infection rate $7.5 \%,>70 y$ rs had the highest infection rate of $30.9 \%$ $\left(\mathrm{X}^{2}\right.$ trend $\left.=4.91 \mathrm{P}<0.0001\right)$.

Table II shows the infection rate by service units among surgical patients at AKTH. While the paediatric ward had the least infection rate of $12.0 \%$, male surgical ward had the highest infection rate of $25.9 \%$. There was a statistically significant difference observed when all the service points were compared $\left(X^{2}=4.41 \mathrm{df} 4\right.$ $\mathrm{P}<0.001)$.

Table III shows some factors as independent predictors of SSI in a multiple logistic regression analysis.

Gender: There was no relationship observed between gender and development of SSI in the study $(\mathrm{P}<0.98$, OR $0.99,95 \% \mathrm{Cl} 0.47-2.09$ ).

Table IV. Types of surgery and infection rate in surgical patients in AKTH

\begin{tabular}{lrrr} 
Type of surgery & No. of patients & No of infection & Percentage infected \\
\hline Emergency C/S & 310 & 56 & 18.1 \\
Elective C/S & 300 & 26 & 8.7 \\
Prostatectomy & 86 & 19 & 22.1 \\
Hydrocelectomy & 46 & 8 & 17.4 \\
Mastectomy & 28 & 3 & 10.7 \\
Abdominal surgery & 1353 & 268 & 19.8 \\
Cystectomy & 140 & 29 & 14.2 \\
Excisional biopsy & 168 & 11 & 6.5 \\
Thyroidectomy & 53 & 4 & 7.5 \\
Fistulectomy & 90 & 33 & 36.6 \\
Debridement & 100 & 76 & 76.0 \\
Uretrotomy & 185 & 45 & 24.3 \\
Cholecystectomy & 21 & 7 & 33.3 \\
\hline
\end{tabular}

$X^{2}=179.12$, df $12 \mathrm{p}<0.001$

$\mathrm{C} / \mathrm{S}=$ Caesarean Section
Age: Age was significantly associated with the risk of infection in this study. When age differences were compared with regard to the risk of postoperative wound infection a higher proportion of old people ( $>60$ years) became infected compared with younger patients. The difference was statistically significant $(\mathrm{P}<0.0001)$. However, after adjusting for other factors such as anaemia, sex, diabetes, duration of surgery, age was no longer a significant predictor of infection $(\mathrm{P}<0.15$, OR 0.97, 95\% Cl $0.92-1.01)$.

Anaemia: Anaemic patients have three and half times the risk for postoperative infection when compared with those without anaemia $(\mathrm{P}<0.002, \mathrm{OR} 3.47,95$ Cl 1.57 - 7.67). Infection rate was $30 \%$.

Duration of surgery: Patients that had longer duration of surgery, above $>2$ hours had almost four times the risk of post operative infection than those that had shorter duration of surgery $<2$ hours $(\mathrm{P}<0.001$, OR $3.77,95 \% \mathrm{Cl} 1.71-8.32)$. The infection rate observed in those that had duration above $2 \mathrm{hrs}$ was $18.7 \%$.

Obesity: Patients considered obese had a five times higher risk of surgical site infection when compared 
with non-obese patient $(\mathrm{P}<0.001$, OR $5.4995 \% \mathrm{Cl}$ $2.46-12.23)$. Infection rate found in obese patients was $33.3 \%$.

Number on operation list: When number on the operation list was considered following the sequence of operations, there was no significant difference observed $(P<0.23)$. Infection rate seen was $5.8 \%$.

Number of personnel in the theatre: A statistically significant difference was observed when the number of personnel in the operating room exceeded 6 persons $(\mathrm{P}<0.02$, OR 2.45, 95\% Cl 1.11 - 5.41). Infection rate observed in operating room having more than 6 persons was $13.9 \%$.

Cigarette smoking: Cigarette smoking as considered in the study did not show a statistically significant difference when compared with non smokers $(\mathrm{P}<0.09$, OR 2.11, 95\% Cl 0.87 - 5.08). Out of 30 smokers, 2 $(6.6 \%)$ were infected.

Diabetes: Patients who were diabetic had six times increased risk of surgical site infection than those who were not diabetic $(\mathrm{P}<0.001$, OR 6.49, 95\% Cl 2.74 15.39). Infection rate was $32 \%$.

Table IV shows the frequency distribution of infection rates among surgical patients. Clean wounds such as excisional biopsy, mastectomy and thyroidectomy showed lower infection rates than others. The difference was statistically significant $\left(X^{2}=179.12\right.$, df $12 \mathrm{P}<0.001)$. Also emergency caesarean operation showed a higher infection rate than elective caesarean surgery. The difference was statistically significant $\left(X^{2}\right.$ $=10.78 \mathrm{df}=1 \mathrm{P}<0.001$ ).

\section{Discussion}

Surgical site infections constitute a global health problem both in economic and human term. Multiplicity of factors influence SSI rate in clinical practice. This could result from the patient undergoing surgery, members of the operating team or the operating room environment.

In the present study, some of the risk factors were evaluated to establish their association or influence on SSI rate in this locality. These include gender, age, duration of surgery, number of persons in the operating room during surgery, anaemia, number of patients on the operating list, cigarette smoking, diabetes and obesity.

An overall infection rate of $20.3 \%$ was observed in this study which is lower than that reported in India $(30.7 \%),{ }^{10}$ in AllMS $24.8 \%{ }^{11}$ and in Aligarh $38.8 \%{ }^{6}$ However, the incidence in this study is much higher than that in other countries, for instance in USA the SSI rate is estimated to be $2.8 \%$ and $2-5 \%$ in European countries. ${ }^{12} \mathrm{~A}$ report from Tehran reported an infection rate of $8.4 \%$ while that from Tanzania observed $19.4 \% .^{5,7}$

There was no relationship observed between gender and SSI in this study $(\mathrm{P}<0.15)$, other researchers had the same finding. ${ }^{13,14}$ Age was also not a predictor of SSI in this study. This report is at variance with the finding from Iran. ${ }^{13}$

In the present study, obesity was associated with SSI to the extent that an obese patient was five times more likely to be infected than non-obese patients. A researcher at Iran reported the same finding. ${ }^{13}$

Multiple logistic regression analysis showed that anaemic patients have three and a half times the risk of postoperative infection than those without anaemia. Another researcher reported a low haematocrit value pre surgery as a risk factor which agrees with the findings in this study. ${ }^{15}$

In the present study, patients that had longer duration of surgery, $>2$ hours, had four times increased risk of postoperative infection when compared with those that had shorter duration of surgery. Some other reports are in agreement with the finding in this study. 13,16

Position of patient on operation list did not influence the rate of infection in this study. This refers to the sequence in which operations are taken during surgery sessions. However, the reports of some other researchers were at variance with the observations in this study. ${ }^{17,10}$

In the present study, cigarette smoking was not found as a significant predictor of postoperative wound 
infection. This may be due to limited number of subjects involved. However, this finding is at variance with the reports of other researchers who all reported a higher incidence of surgical wound infection in cigarette smokers than in non-smokers and abstinence before surgery. ${ }^{18,5}$ This is because of local systemic vasoconstriction causing tissue hypoxia, which delays primary wound healing.

High blood sugar can increase infection rate and impair wound healing. Poorly controlled diabetes adversely affects the ability of leukocytes to destroy invading bacteria and to prevent the harmful proliferation of usually benign bacteria present in the healthy body. A six times higher risk of postoperative wound infection in diabetic patients than non-diabetic was observed in the present study. This agrees with the findings of other researchers who all reported increased predisposition of diabetes to surgical wound infection in their different centres. ${ }^{10,19,20}$

Emergency surgical interventions, as shown with caesarean surgery in this study, increased the rate of surgical site infection. The higher infection rate in emergency operation is attributed to inadequate preoperative preparation and the severity of the underlying condition that necessitated emergency procedure. ${ }^{11,14,}$ 21

The number of people in the operating room theatre during surgery affected the infection rate. This increased with increase in the number of people. This finding is in agreement with the report of another researcher in Belgrade. $^{22}$

It is important to employ strict infection control policies by a functional well funded infection control committee. This committee should be able to monitor surveillance studies in the locality with a view to issuing guidelines to circumvent established risk factors. This would bring the level of SSI to an acceptable level.

\section{References}

1. Skayzynska J, Ciencala A, Madry R, et al. Hospital infection in general surgery wards. Przegl Epidemiol 2000; 54(3-4): 299304.

2. Troillet N, Petignant C, Matter M, Eisenring MC, Mosimann F, Francioli P. Surgical Site Infection surveillance: an effective preventive measure. Rev Med Suisse Romande 2001; 121(2): 125-128.

3. Dionigi R, Rovera F, Dionigi G, et al. Risk factors in surgery. J Chemother 2001; 13: 6-11.
4. Bowler PG, Duerden BI, Armstrong DG. Wound microbiology and associated approaches to wound mamagement. Clin Microbial Rev 2001; 14: 244-269. http://dx.doi.org/10.1128/ CMR.14.2.244-269.2001

5. Arabashahi KS, Koohpayezade J. Investigation of risk factors for surgical wound infection among teaching hospitals in Tehran. Int Wound / 2006; 3: 59-62. http://dx.doi. org/10.1111/j.1742-4801.2006.00176.x

6. Ganguly PS, Khan Y, Malik A. Nosocomial infection and hospital procedures. Indian J Common Med 2000; 990-1014.

7. Eriksen HM, Chugulu S, Kondo S, Lingaas E. Surgical site infections at Kilimanjaro Christian Medical Centre. I Hosp Infect 2003; 55: 14-20. http://dx.doi.org/10.1016/S01956701(03)00225-1

8. Collier M. Recognition and management of wound infections. World Wide Wounds 2004.

9. Whiting P, Rutjes AWS, Reitsma JB, Bossuyt PMM, Kleijen J. The development of QUADAS: a tool for the quality assessment of studies of diagnostic accuracy included in systematic reviews. BMC Med Res Meth 2003; 3: 25. http:// dx.doi.org/10.1186/1471-2288-3-25

10. Kamat US, Fereirra AMA, Kulkarni MS, Motghare DD. A prospective study of surgical site infections in a teaching hospital in Goa. Ind I Surg 2008; 70: 120-124.

11. Subramanian KA, Prakash A, Shriniwas, Bhujwala RA. Post operative wound infection. Ind / Surg 1973; 57 - 64.

12. Dellinger EP, Ehrankranz NJ. Surgical infections. In Hospital infections, $4^{\text {th }}$ edn. Edited by Bennett JV, Brachmann PS. Lippincott Williams \& Wilkins 1998.

13. Razavi MS, Ibrahimpoor $M$, Kashani AS, Jafarian A. Abdominal surgical site infections: incidence and risk factors at an Iranian teaching hospital. BMC Surgery 2005; 5: 2. doi: 10.1186/147-2482-5-2

14. Bibi S, Channa AG, Siddiqui RT, Ahmed W. Frequency and risk factors of surgical site infections in general surgery ward of a tertiary care hospital of Karachi, Pakistan. Int J Infect Control 2011; 7(3).

15. Dune JR, Malone D, Tracy K, Gannon C, Napolitano ML. Perioperative Anemia: An independent risk factor for infection, Mortality, and Resource Utilization in surgery. I Hosp Infect 1995; 29(4): 305-309.

16. Narong MA, Thongpiyapoom S, Thaikul N, Jamulitrat S, Kasatpibal N. Surgical site infections in patients undergoing major operations in a university hospital: using standard infection ratio as a bench mark tool. Am J Infect Control 2003; 31(5): 274-297. http://dx.doi.org/10.1067/mic.2003.65

17. deSa LA, Sathe MJ, Bapat RD. Factors influencing wound infection (a prospective study of 280 cases). J Postgard Med 1984; 30: 232-236.

18. Sorenson LT, Karlsmark T, Gottrup F. Abstinence from smoking reduces incisional wound infection: a randomized controlled trail. Ann Surg 2003; 238: 1-5. http://dx.doi.org/10.1097/01. SLA.0000074980.39700.31

19. Alsaimary IEA. Bacterial wound infections in diabetic patients and their therapeutic implications. Med Pract Rev 2010; 1(2): 12-15.

20. Ibrahim MK, Salama MS, Mustafa RM. Studies on surgical wound nosocomial infections. J Union Arab Biol Cairo 1998; 6(13): 115-128.

21. Petrosillo N, Drapeau CM, Nicastri E, Martini L, Ippolito G, Moro ML. Surgical site infections in Italian Hospitals: a prospective multicenter study. BMC Infect Dis 2008; 8: 34. http://dx.doi.org/10.1186/1471-2334-8-34

22. Maksimović J, Marković-Denić L, Bumbaširević $M$, Marinković J, Vlajinac H. Surgical Site Infections in Orthopedic Patients: Prospective Cohort Study. Croat Med J 2008; 49(1): 58-65. http://dx.doi.org/10.3325/cmj.2008.1.58 